\title{
Pengaruh Service Excellence, Servicescape Dan Handling Complaint Terhadap Kepuasan Pelanggan Restoran
}

\author{
Adiyoga Pradana Sakti, Sulistiono, Danti Astrini \\ Program Studi Manajemen, Institut Bisnis dan Informatika Kesatuan \\ Program Studi Bio Kewirausahaan, Institut Bisnis dan Informatika Kesatuan \\ Bogor, Indonesia
}

E-Mail: adiyogaps@ibik.ac.id
Submitted: OKTOBER 2020

\section{ABSTRAK}

Untuk dapat meningkatkan kepuasaan Pelanggan, perusahaan dituntut untuk memiliki strategi yang tepat agar dapat membangun hubungan yang baik dengan pelanggannya. Kualitas pelayanan, Strategi Lokasi, dan Harga dapat menjadi faktor bagi perusahaan untuk meningkatkan kepuasaan pelanggan. Tujuan penelitian ini adalah untuk mengetahui Pengaruh Service Excellence, Servicescape dan Handling Complaint Terhadap Kepuasan Pelanggan pada pelayanan Restoran Cimory Riverside. Total responden dalam penelitian ini adalah 100 Responden diambil dari pengunjung Restoran Cimory Riverside menggunakan Purposive Sampling. Data yang digunakan dalam penelitian ini adalah data primer. Data dianalisis melalui uji validitas, uji reliabilitas, uji asumsi klasik, koefisien korelasi, koefisien determinasi, analisis regresi berganda, uji $\mathrm{T}$ dan uji F. Pengolahan data menggunakan SPSS versi 22. Dari hasil analisis menunjukan bahwa secara parsial (1) terdapat hubungan positif dan signifikan antara Service Excellence dengan Kepuasan Pelanggan. (2) terdapat hubungan positif dan signifikan antara Servicescape dengan Kepuasan Pelanggan. (3) terdapat hubungan positif dan namun tidak signifikan antara Handling Complaint dengan Kepuasan Pelanggan. Dan secara simultan, (4) terdapat hubungan positif dan signifikan antara Service Excellence dan Servicescape dengan Kepuasan Pelanggan. (5) terdapat hubungan positif namun tidak signifikan antara Service Excellence dan Handling Complaint dengan Kepuasan Pelanggan. (6) terdapat hubungan positif dan signifikan antara Servicescape dan Handling Complaint dengan Kepuasan Pelanggan. (7) Service Excellence, Servicescape, Handling Complaint secara bersama-sama berpengaruh positif dan signifikan terhadap Kepuasan Pelanggan.

KataKunci: service excellence, servicescape, handling complaint, kepuasan pelanggan

\section{PENDAHULUAN}

Permintaan pasar telah bergeser ke era leisure economy dimana konsumen mulai bergeser perilakunya dari konsumsi barang (goods-based consumption) ke konsumsi pengalaman (experience-based consumption). Konsumen pun berubah menjadi apa yang disebut sebagai leisumer (leisure consumers). Experience-based consumption seperti liburan, dine-out, nongkrong di kafe, menonton konser, gym, yoga, hingga online games meningkat pesat menjadikan sektor leisure tumbuh begitu cepat melampaui sektor-sektor yang lain tidak terkecuali sektor restoran yang kini tengah meningkatkan kualitas layanannya untuk memenuhi konsumen yang telah berubah perilakunya. Menciptakan nilai dan kepuasan pelanggan

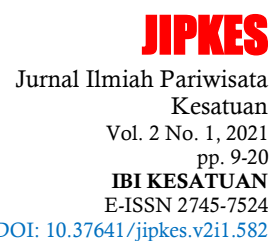


Restaurant's

Customer

Satisfaction

\section{0}

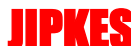

Jurnal Ilmiah Pariwisata

Kesatuan

Vol. 2 No. 1, 2021

pp. 9-20

IBI KESATUAN

E-ISSN 2745-7524

DOI: $10.37641 /$ jipkes.v2i1.582 adalah inti pemikiran pemasaran modern berbasis leisure. Tujuan kegiatan pemasaran adalah menarik pelanggan baru dengan menjanjikan nilai yang tepat dan mempertahankan pelanggan saat ini dengan memenuhi harapannya sehingga dapat menciptakan tingkat kepuasan.

Pertumbuhan industri makanan dan minuman naik terus meningkat. Sebagai contoh di 2017 pertumbuhannya mencapai 9,23\% atau naik dari 2016 yang sebesar 8,46\%. Selain itu kontribusi industri mamin ke PBD juga cukup besar. Industri makanan dan minuman kontribusi ke PDB non migas 34,33\%. Pertumbuhan industri makanan dan minuman dan minuman pada tahun 2017 mencapai sebear 9,23\%, mengalami peningkatan bila dibandingkan dengan tahun 2016 sebesar 8,46 (Kementerian Perindustrian). Pertumbuhan industri mamin membantu pemerataan ekonomi karena mayoritas pelakunya di sektor UKM. Hal ini menunjukan industri mempunyai peran yang besar dalam pertumbuhan ekonomi Indonesia. Perusahaan makanan dan minuman sudah mulai mengimplementasikan industri 4.0. Hal tersebut dilakukan supaya industri mamin Indonesia tidak tergerus dengan zaman yang tengah berkembang. Menurut data BPS, pertumbuhan konsumsi restoran dan hotel sepanjang tahun 2017 ini tercatat di angka 5,53 persen atau tumbuh dibanding tahun sebelumnya yakni 5,40 persen.

Riset Inventures Indonesia melansir, ada 64 persen generasi millenials yang meluangkan waktu dan biaya untuk makan di restoran setidaknya satu kali dalam sebulan. Bahkan, 30 persen millenials di antaranya menyambangi restoran hingga lima dalam sebulan. Millenials merogoh kocek paling sedikit Rp50 ribu - Rp100 ribu untuk satu kali makan di restoran. Apalagi, aktivitasnya tak sekadar makan. Inventures menyebut 83 persen respondennya yang merupakan millenials bahkan pergi ke restoran untuk bersosialisasi. Hal ini yang menyebabkan pertumbuhan pada sektor industri kuliner yang membuat perusahaan harus bisa memenuhi kebutuhan dan juga keingingan dari para konsumennya

Fenomena yang berkenaan dengan perubahan perilaku konsumen menjadi leisure based consumption, pertumbuhan industri kuliner pada revolusi industri 4.0 dan banyaknya restoran yang tersebar di Kabupaten dan Kota Bogor berimplikasi pada tingkat kepuasan konsumen yang standarnya akan terus meningkat. Pada bisnis restoran yang harus menjadi salah satu perhatian dari pemilik atau Pengelola adalah kesan pertama bagi kosumen dalam menikmati makanan yang dihidangkan oleh restoran. Kesan pertama dalam menikmati makanan tersebut, apakah makanan yang dihidangkan tersebut dapat memuaskan konsumen, sehingga memberikan citra yang baik bagi konsumen. Selain menikmati hidangan makanan yang biasanya disajikan untuk memperoleh kepuasan konsumen saat ini juga harus menyuguhkan added value yang berbeda lebih dari sekedar makanan dan minuman.

Untuk mencapai kepuasan konsumen yang maksimal sekarang semakin banyak bisnis restoran menyadari arti pentingnya serta menerapkan excellent service untuk membangun daya saing selain kualitas produk yang dihasilkan serta harga kompetitif yang ditawarkan, karena aspek tersebut merupakan satu kesatuan yang tidak dapat dipisahkan. Sisi prosedur dari pelayanan terdiri dari sistem dan prosedur yang mapan untuk menyerahkan produk atau jasa. Sisi pribadi dari pelayanan adalah bagaimana personal pelayanan (dengan menggunakan sikap, perilaku, dan keterampilan verbal) dalam berinteraksi dengan pelanggan. Pelayanan yang diberikan oleh restoran tidak boleh hanya sekedar untuk mencukup kebutuhan konsumen, tetapi bagaimana agar konsumen mendapatkan pelayanan lebih dari yang diharapkan, sehingga konsumen merasa puas terhadap 
apa yang didapatkannya dan menjadi loyal terhadap restoran karena selalu menyuguhkan pelayanan yang membuat konsumen tidak rugi untuk datang kembali ke restoran.

Service excellence merupakan unsur penting yang memiliki kaitan erat dengan keberhasilan perusahaan dalam mempertahankan konsumen dengan melayani sampai konsumen mencapai tingkat kepuasan dan menjadi loyal terhadap perusahaan. Selanjutnya, service excellence harus menjadi bagian dari budaya perusahaan yang tercermin dalam visi, misi dan komitmen perusahaan Merancang lingkungan layanan adalah sebuah seni yang menyita banyak waktu dan usaha, dan dapat menjadi mahal dalam penerapannya. Lingkungan layanan juga dikenal sebagai servicescape. Ruang lingkup servicescape dapat mengenali pentingnya dari lingkungan fisik sekitar dari karyawan dan juga pelanggannya

Dalam pelaksanaan operasional restoran, seringkali terdapat complaint pelanggan baik secara langsung maupun tidak langsung (melalui berbagai media). Complaint pelanggan merupakan ungkapan ketidakpuasan pelanggan yang disebabkan oleh ketidakpuasan yang diduga akibat kesalahan atau kelalaian pihak restoran. Penanganan perlu dilakukan secara bijaksana karena apabila tidak diselesaikan dengan baik oleh pihak restoran akan menjadi perselisihan atau sengketa yang pada akhirnya akan dapat merugikan perusahaan. Complaint, keluhan atau pengaduan yang tersebar kepada publik melalui berbagai media apabila tidak segera ditanggulangi akan dapat menurunkan kepercayaan masyarakat pada restoran pada umumnya dan reputasi restoran tersebut pada khususnya. Oleh karena itu untuk mengurangi permasalahan mengenai complaint pelanggan maka sangat diperlukan pengelolaan dan penanganan complaint yang baik.

Jika dilihat dari sales restoran cimory memang tidak ada masalah berarti tetapi cimory tidak mau berpuas diri. Menurut beliau meningkatkan kualitas pelayanan adalah hal kunci untuk mempertahankan dan juga meningkatkan kepuasan konsumen yang berkunjung ke restoran cimory. Setiap orang memiliki faktor dan tingkat kepuasan yang berbeda namun ada karakteristik dari restoran yang menjadi faktor kepuasan selain kualitas layanan itu sendiri yaitu, lingkungan layanan mendukung dan penanganan keluhan yang baik. Dalam hal lingkungan layanan, restoran cimory mempunyai lingkungan yang sangat luas dengan berbagai macam fungsi. Hal ini dapat mempengaruhi kepuasan konsumen jika dikelola dengan baik dan benar namun tetap saja setiap bisnis yang berjalan pasti tidak ada yang sempurna pasti ada saja komplain yang datang tidak terkecuali restoran cimory. Menurut google review dan beberapa laporan dari karyawan ada beberapa komplain diantaraya: makanannya yang disajikan tidak hangat, harganya yang mahal dan pelayanan yang kurang memuaskan. Komplain komplain seperti ini yang pastinya ingin di minimalisir dengan berbagai cara.

\section{METODE PENELITIAN}

Penelitian ini menggunakan variabel independen (Service Excellence, Servicescape dan Handling Complaint) dan variabel dependen (Kepuasan Pelanggan). Total responden dalam penelitian ini adalah 100 Responden diambil dari pengunjung Restoran Cimory Riverside sebagai pengunjung restoran Cimory Riverside menggunakan Non-probability Sampling dengan menggunakan Purposive Sampling yaitu teknik dalam pengambilan sampel dengan pertimbangan kriteria tertentu yang telah ditetapkan terlebih dahulu oleh peneliti. Data yang digunakan dalam penelitian ini adalah data primer. Pengambilan
Restaurant's

Customers

Satisfaction

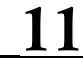

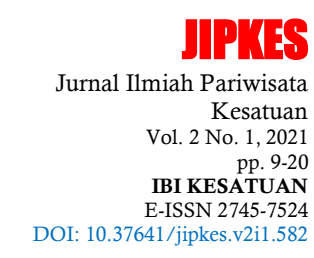


Restaurant's

Customer

Satisfaction

12

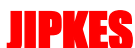

Jurnal Ilmiah Pariwisata Kesatuan

Vol. 2 No. 1, 202

pp. 9-20

IBI KESATUAN

E-ISSN 2745-7524

DOI: $10.37641 /$ jipkes.v2i1.582 sampel berdasarkan rumus Roscoe. Data dianalisis melalui uji validitas, uji reliabilitas, uji asumsi klasik, koefisien korelasi, koefisien determinasi, analisis regresi berganda, uji T dan uji F. Pengolahan data menggunakan SPSS versi 22.

\section{HASIL DAN PEMBAHASAN}

\section{Uji Kualitas Data}

Berdasarkan hasil uji validitas untuk indikator variabel service excellence diperoleh nilai r-product moment hitung dari pertanyaan satu sampai dengan enam dimulai dari 0,$781 ; 0,748 ; 0,642 ; 0,587 ; 0,643 ; 0,778 ; 0,769$ dengan nilai signifikansi sebesar 0,000 atau dibawah $5 \%$, atau bisa juga dikatakan nilai $r$-product moment hitung lebih besar dari r-product moment tabel $(n=100, \alpha=5 \%)=0,195$, dengan demikian maka seluruh pertanyaan dalam kuesioner X1 (Service Excellence) dapat dipergunakan untuk penelitian selanjutnya. Demikian pula untuk indikator variabel servicescape diperoleh pula nilai r-product moment hitung dari pertanyaan satu sampai dengan empat dimulai dari 0,$613 ; 0,747 ; 0,732 ; 0,735 ; 0,713 ; 0,664$ dengan nilai signifikansi sebesar 0,000 atau dibawah $5 \%$, atau bisa juga dikatakan nilai r-product moment hitung lebih besar dari r-product moment tabel $(\mathrm{n}=100, \alpha=5 \%)=0,195$, dengan demikian maka seluruh pertanyaan dalam kuesioner X2 (Servicescape) dapat dipergunakan untuk penelitian selanjutnya. Untuk indikator variabel handling complaint, diperoleh nilai r-product moment hitung dari pertanyaan satu sampai dengan delapan dimulai dari 0,$855 ; 0,881 ; 0,868$; 0,$901 ; 0,838$ ) dengan nilai signifikansi sebesar 0,000 atau dibawah $5 \%$, atau bisa juga dikatakan nilai r-product moment hitung lebih besar dari r-product moment tabel $(\mathrm{n}=100, \alpha=5 \%)=0,195$, dengan demikian maka seluruh pertanyaan dalam kuesioner X3 (Handling Complaint) dapat dipergunakan untuk penelitian selanjutnya. Uji validitas untuk indikator variabel kepuasan pelanggan diperoleh nilai r-product moment hitung dari pertanyaan satu sampai dengan tujuh dimulai dari 0,$703 ; 0,759 ; 0,721 ; 0,646 ; 0,737$ dengan nilai signifikansi sebesar 0,000 atau dibawah 5\%, atau bisa juga dikatakan nilai r-product moment hitung lebih besar dari $r$-product moment tabel $(n=100, \alpha=5 \%)=0,195$, dengan demikian maka seluruh pertanyaan dalam kuesioner Y (Kepuasan Pelanggan) dapat dipergunakan untuk penelitian selanjutnya.

Uji reliabilitas adalah proses pengukuran terhadap ketepatan (konsisten) dari suatu instrumen. Pengujian ini dimaksudkan untuk menjamin instrumen yang digunakan dan segala instrumen tersebut merupakan sebuah instrumen yang handal, konsistensi, stabil dan dependibalitas, sehingga bila digunakan berkali-kali dapat menghasilkan data yang sama. Suatu konstruk atau variabel dikatakan reliable jika nilai alpha cronbach $>0,60$ dan sebaliknya jika nilai alpha cronbach $<0,60$ maka variabel tersebut tidak reliable.

Tabel 1 Hasil Uji Reliabilitas Varianel Service Excellence, Servicescape, Handling Complaint dan Kepuasan Pelanggan

\begin{tabular}{lcccc}
\hline \multicolumn{1}{c}{ Variabel } & $\begin{array}{c}\text { Cronbach' } \\
\text { s Alpha }\end{array}$ & $\begin{array}{c}\text { Cronbach's Alpha based } \\
\text { on Standarized Items }\end{array}$ & $\begin{array}{c}\text { N of } \\
\text { Items }\end{array}$ & Ket \\
\hline Service Excellence & 0,706 & 0,600 & 8 & Reliable \\
Servicescape & 0,776 & 0,600 & 7 & Reliable \\
Handling Complaint & 0,820 & 0,600 & 6 & Reliable \\
Kepuasan & 0,779 & 0,600 & 6 & Reliable \\
Pelanggan & & & & \\
\hline
\end{tabular}

Sumber: Data Primer yang diolah dengan SPSS, 2019 
Hasil nilai Cronbach's Alpha variable Service Excellence, Servicescape, Handling Complaint dan Kepuasan Pelanggan lebih besar dari Standar Reliabilitas sebesar 0,600. Sehingga kuesioner/indikator yang digunakan oleh keempat variable handal atau dapat dipercaya sebagai alat ukur variabel yaitu apabila dilakukan pengukuran ulang maka data yang didapat akan konsisten dari waktu ke waktu.

Pengujian normalitas dalam penelitian ini dilakukan dengan memperhatikan normal probability plot yang membandingkan distribusi kumulatif dari data sesungguhnya dengan distribusi kumulatif dari data normal.

Tabel 2 Hasil Uji Normalitas

One-Sample Kolmogorov-Smirnov Test

\begin{tabular}{llc}
\hline & & Unstandardized Residual \\
\hline Normal Parameters & & 100 \\
\cline { 2 - 3 } & Mean & .0000000 \\
\cline { 2 - 3 } Most Extreme Differences & Std. Deviation & 1.80327932 \\
\cline { 2 - 3 } & Absolute & .063 \\
\cline { 2 - 3 } & Positive & .063 \\
\hline Test Statistic & -.048 \\
\hline Asymp. Sig. (2-tailed) & .063 \\
a. Test distribution is Normal. & $.200^{c, d}$ \\
b. Calculated from data. & \\
c. Lilliefors Significance Correction. & \\
d. This is a lower bound of the true significance.
\end{tabular}

Sumber: Data yang diolah dengan SPSS,2019

Berdasarkan tabel 2, diketahui bahwa nilai signifikansi sebesar 0,200 lebih besar dari pada 0,05 , sehingga dapat disimpulkan bahwa data yang saya uji berdistribusi normal

Uji multikolinieritas bertujuan untuk menguji apakah dalam model regresi ditemukan adanya korelasi antar variabel bebas. Model regresi yang baik seharusnya tidak terjadi korelasi diantara variabel bebas. Multikolinieritas dideteksi dengan menggunakan nilai tolerance dan Variance Inflation Factor (VIF). Tolerance mengukur variabilitas variabel bebas yang terpilih dan tidak dapat dijelaskan oleh variabel bebas lainnya.

Tabel 3 Hasil Uji Multikolinearitas

\begin{tabular}{ccc}
\multirow{2}{*}{ Model } & \multicolumn{2}{c}{ Collinearity Statistics } \\
\cline { 2 - 3 } (Constant) & Tolerance & VIF \\
\hline Total_SE & & 2.578 \\
\hline Total_SS & .388 & 1.849 \\
\hline Total_HC & .541 & 2.500
\end{tabular}

Sumber: Data Primer yang diolah dengan SPSS, 2019

Dari tabel 3, dapat dilihat nilai tolerance untuk Service Excellece sebesar 0,388, Servicescape sebesar 0,541 dan Handling Complaint sebesar 0,400. Nilai tolerance diatas 0,1 sehingga dapat disimpulkan bahwa tidak terjadi multikolinearitas antar variabel bebas. Uji Multikolinearitas dapat pula dilakukan dengan cara membandingkan VIF (Variance Inflation Factor) dibawah 10. Jika nilai VIF $<10$ maka tidak terjadi multikolinearitas. Hasil pengujian variabel bebas VIF untuk Service Excellence sebesar 2,578, Servicescape sebesar 1,849 dan Handling Complaint
Restaurant's

Customers

Satisfaction

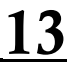


Restaurant's

Customer

Satisfaction

14

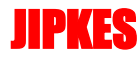

Jurnal Ilmiah Pariwisata Kesatuan

Vol. 2 No. 1,2021 pp. 9 -20

DISEATUAN

E-ISSN 2745-7524

DOI: $10.37641 /$ jipkes.v2i1.582 sebesar 2,500. Dari hasil pengujian tersebut dapat disimpulkan bahwa tidak terjadi multikolinearitas antar variabel bebas. Dengan demikian uji asumsi klasik tidak adanya multikolinearitas dapat dipenuhi.

Berdasarkan hasil pengujian dibawah diketahui bahwa semua variabel independen secara statistik baik X1 (Service Excellence), X2 (Servicescape), dan X3 (Handling Complaint) mempunyai nilai sig $>0,05$ atau diatas 5\%, maka dapat disimpulkan bahwa tidak terjadi heteroskedastisitas dalam model regresi. Tabel 4. Hasil Uji Heteroskedastisitas

\begin{tabular}{|c|c|c|c|c|c|c|}
\hline \multirow{2}{*}{\multicolumn{2}{|c|}{ Model }} & \multicolumn{2}{|c|}{$\begin{array}{l}\text { Unstandardized } \\
\text { Coefficients }\end{array}$} & \multirow{2}{*}{$\begin{array}{c}\text { Standardized } \\
\text { Coefficients }\end{array}$} & \multirow[b]{2}{*}{$\mathrm{t}$} & \multirow[b]{2}{*}{ Sig. } \\
\hline & & $\mathrm{B}$ & Std. Error & & & \\
\hline 1 & (Constant) & 1.467 & 1.167 & & 1.257 & .212 \\
\hline & Total_SE & -.021 & .059 & -.059 & -.364 & .717 \\
\hline & Total_SS & -.007 & .055 & -.017 & -.121 & .904 \\
\hline & Total_HC & .037 & .056 & .106 & .659 & .512 \\
\hline
\end{tabular}

a. Dependent Variable: Abs_Res

Sumber: Data Primer yang diolah dengan SPSS, 2019

Berdasarkan tabel 4. hasil perhitungan tersebut menunjukkan tidak ada gangguan heteroskedastisitas yang terjadi dalam proses estimasi parameter model penduga dari output diatas. Sehingga secara keseluruhan dapat disimpulkan bahwa tidak ada masalah heteroskedastisitas karena nilai 0,212 lebih besar dari 0,005

\section{Analisis Korelasi}

Analisis Korelasi digunakan untuk mengetahui arah dan kuat atau tidaknya hubungan antara variabel Service Excellence, Servicescape, Handling Complaint dan Kepuasan Pelanggan maka dari itu dilakukannya analisis korelasi. Hasil analisis dari korelasi adalah koefisien korelasi yang menunjukkan kuat atau lemahnya dari suatu hubungan. Sedangkan untuk membuktikan ada tidaknya pengaruh antar variabel akan dilakukan analisis regresi secara simultan untuk masing-masing variabel pada masing-masing variabel.

Tabel 5 Korelasi Antar Variabel

\begin{tabular}{|c|c|c|c|c|c|}
\hline \multirow{4}{*}{$\frac{\text { Keterangan }}{\text { Total_SE }}$} & & Total_SE & Total_SS & Total_HC & Total_KP \\
\hline & Pearson Correlation & 1 & $.641^{* *}$ & $.751^{* *}$ & $.706^{* \star}$ \\
\hline & Sig. (2-tailed) & & .000 & .000 & .000 \\
\hline & $\mathrm{N}$ & 100 & 100 & 100 & 100 \\
\hline \multirow[t]{3}{*}{ Total_SS } & Pearson Correlation & $.641^{* *}$ & 1 & $.627^{* \star}$ & $.608^{* *}$ \\
\hline & Sig. (2-tailed) & .000 & & .000 & .000 \\
\hline & $\mathrm{N}$ & 100 & 100 & 100 & 100 \\
\hline \multirow[t]{3}{*}{ Total_HC } & Pearson Correlation & $.751^{* *}$ & $627^{* *}$ & 1 & $.632^{* *}$ \\
\hline & Sig. (2-tailed) & .000 & .000 & & .000 \\
\hline & $\mathrm{N}$ & 100 & 100 & 100 & 100 \\
\hline \multirow[t]{3}{*}{ Total_KP } & Pearson Correlation & $.706^{* *}$ & $608^{* *}$ & $.632^{* *}$ & 1 \\
\hline & Sig. (2-tailed) & .000 & .000 & .000 & \\
\hline & $\mathrm{N}$ & 100 & 100 & 100 & 100 \\
\hline
\end{tabular}

**. Correlation is significant at the 0.01 level (2-tailed).

Sumber: Data Primer yang diolah dengan SPSS, 2019

Tabel 5 menunjukkan bahwa variabel Service Excellence berkorelasi positif sebesar 0,641 terhadap variabel Servicescape dan dapat disimpulkan bahwa kedua variabel tersebut terdapat korelasi yang signifikan antara variabel yang 
dihubungkan. Kemudian variabel Service Excellence berkorelasi positif sebesar 0,751 terhadap variabel Handling Complaint dan dapat disimpulkan bahwa kedua variabel tersebut terdapat korelasi yang signifikan antara variabel yang dihubungkan. Tabel 5 pun menunjukkan bahwa variabel Service Excellence berkorelasi positif sebesar 0,706 terhadap variabel Kepuasan Pelanggan dan dapat disimpulkan bahwa kedua variabel tersebut terdapat korelasi yang signifikan antara variabel yang dihubungkan

Berdasarkan tabel 5 dapat dinyatakan bahwa variabel Servicescape berkorelasi positif sebesar 0,627 terhadap variabel Handling Complaint dan dapat disimpulkan bahwa kedua variabel tersebut terdapat korelasi yang signifikan antara variabel yang dihubungkan, variabel Servicescape berkorelasi positif sebesar 0,608 terhadap variabel Kepuasan Pelanggan dan dapat disimpulkan bahwa kedua variabel tersebut terdapat korelasi yang signifikan antara variabel yang dihubungkan, bahwa variabel Handling Complaint berkorelasi positif sebesar 0,632 terhadap variabel Kepuasan Pelanggan dan dapat disimpulkan bahwa kedua variabel tersebut terdapat korelasi yang signifikan antara variabel yang dihubungkan

Analisis Regresi Berganda

Tabel 6 Hasil Analisis Regresi Berganda

\begin{tabular}{|c|c|c|c|c|c|c|}
\hline & \multirow[t]{2}{*}{ Model } & \multicolumn{2}{|c|}{$\begin{array}{l}\text { Unstandardized } \\
\text { Coefficients }\end{array}$} & \multirow{2}{*}{$\begin{array}{c}\begin{array}{c}\text { Standardized } \\
\text { Coefficients }\end{array} \\
\text { Beta }\end{array}$} & \multirow[t]{2}{*}{$\mathrm{t}$} & \multirow[t]{2}{*}{ Sig. } \\
\hline & & $\mathrm{B}$ & Std. Error & & & \\
\hline \multirow{4}{*}{1} & (Constant) & .867 & 1.864 & & .465 & .643 \\
\hline & Total_SE & .379 & .094 & .443 & 4.031 & .000 \\
\hline & Total_SS & 213 & .088 & .226 & 2.424 & .017 \\
\hline & Total HC & .130 & .090 & .157 & 1.451 & .150 \\
\hline
\end{tabular}

a. Dependent Variable: Total_KP

Sumber: Data Primer yang diolah dengan SPSS, 2019

Berdasarkan tabel 6 dapat ditentukan persamaan regresi berganda untuk penelitian ini sebagai berikut:

$\mathrm{Y}=0,867+0,379 x_{1}+0,213 x_{2}+0,130 x_{3}+$ error

Berdasarkan persamaan regresi diatas, jika;

a. $\mathrm{X} 1=\mathrm{X} 2=\mathrm{X} 3=0$, maka $\mathrm{Y}$ nilainya sebesar 0,867

b. Jika X1 naik sebesar 1 (satu) satuan maka Y akan turun sebesar 0,379 jika variabel lain dianggap konstan

c. Jika X2 naik sebesar 1 (satu) satuan maka Y akan turun sebesar 0,213 jika variabel lain dianggap konstan

d. Jika X3 naik sebesar 1 (satu) satuan maka Y akan turun sebesar 0,130 jika variabel lain dianggap konstan

\section{Koefisien Korelasi dan Determinasi}

Koefisien Determinasi $\left(\mathrm{R}^{2}\right)$ adalah satu ukuran untuk mengukur kontribusi pengaruh antara variabel $\mathrm{X}$ (independen) terhadap variabel $\mathrm{Y}$ (dependen), dengan $0<\mathrm{R}^{2}<1$.

Tabel 7 Koefisien Korelasi dan Determinasi

\begin{tabular}{ccccc}
\hline Model & R & R Square & Adjusted R Square & Std. Error of the Estimate \\
\hline 1 & $.741^{\mathrm{a}}$ & .550 & .536 & 1.831 \\
\hline
\end{tabular}

a. Predictors: (Constant), Total_HC, Total_SS, Total_SE

b. Dependent Variable: Total_KP

Berdasarkan tabel 6 hasil output model summary dapat dijelaskan bahwa hubungan atau korelasi berganda pada seluruh variabel (Service Excellence. 
Restaurant's

Customer

Satisfaction

$\underline{16}$

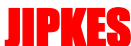

Jurnal Ilmiah Pariwisata

Kesatuan

Vol. 2 No. 1, 2021

pp. $9-20$

IBI KESATUAN

E-ISSN 2745-7524

DOI: 10.37641 /jipkes.v2i1.582
Servicescape, Handling Complaint dan Kepuasan Pelanggan) memiliki kekuatan hubungan yang kuat. Hal ini dapat dilihat berdasarkan nilai koefisien korelasi berganda sebesar 0,741. Perolehan nilai koefisien determinasi r-square sebesar 0,550 dapat dijelaskan bahwa variabel Service Excellence, Servicescape, Handling Complaint dan Kepuasan Pelanggan mampu mempengaruhi atau menjelaskan keragaman (variabilitas). Nilai dari Kepuasan Pelanggan sebesar 55,0\% sedangkan sisanya sebesar 45,0\% $(100 \%-55,0 \%=45,0 \%)$ dipengaruhi diluar model atau dijelaskan oleh variabel lain yang tidak diteliti.

Uji Hipotesis Statistik

Untuk menunjukkan hubungan Service Excellence (X1) dengan Kepuasan Pelanggan (Y), Servicescape (X2) dengan Kepuasan Pelanggan (Y), Handling Complaint (X3) dengan Kepuasan Pelanggan (Y) berdasarkan tabel 6 dengan $\alpha=$ $5 \%$, df1 = 3 df2= 96 maka:

a. Diperoleh t hitung sebesar 4,031 dan t tabel sebesar 1,984 dengan demikian maka t hitung lebih besar dari t tabel atau $(4,031>1,984)$ dan bernilai signifikansi. Dengan demikian hipotesis satu diterima, $\mathrm{H}_{0}$ ditolak dan $\mathrm{H}_{1}$ diterima berarti ada hubungan positif dan signifikan antara Service Excellence dengan Kepuasan Pelanggan.

b. Diperoleh $\mathrm{t}$ hitung sebesar 2,424 dan $\mathrm{t}$ tabel sebesar 1,984 dengan demikian maka $t$ hitung lebih besar dari t tabel atau $(2,424>1,984)$ dan bernilai signifikansi. Dengan demikian hipotesis dua diterima, $\mathrm{H}_{0}$ ditolak dan $\mathrm{H}_{2}$ diterima berarti terdapat hubungan positif dan signifikan antara Servicescape dengan Kepuasan Pelanggan.

c. Diperoleh t hitung sebesar 1,451 dan t tabel sebesar 1,984 dengan demikian maka $t$ htitung lebih kecil dari t tabel atau $(1,451<1,984)$ dan bernilai signifikansi. Dengan demikian hipotesis tiga diterima, $\mathrm{H}_{0}$ diterima dan $\mathrm{H}_{3}$ ditolak berarti terdapat hubungan positif namun tidak signifikan antara Handling Complaint dengan Kepuasan Pelanggan.

\section{Uji F (Uji Simultan)}

Tabel 7 Hasil Uji Simultan pengaruh variabel service excellence dan servicescape terhadap kepuasan Pelanggan

\begin{tabular}{ccccccc}
\hline \multirow{2}{*}{ Model } & $\begin{array}{c}\text { Sum of } \\
\text { Squares }\end{array}$ & Df & $\begin{array}{c}\text { Mean } \\
\text { Square }\end{array}$ & F & Sig. \\
\hline \multirow{2}{*}{1} & Regression & 385.763 & 2 & 192.882 & 56.870 & $.000^{\mathrm{b}}$ \\
\cline { 2 - 7 } & Residual & 328.987 & 97 & 3.392 & & \\
\cline { 2 - 7 } & Total & 714.750 & 99 & & & \\
\hline
\end{tabular}

a. Dependent Variable: Total_KP

b. Predictors: (Constant), Total_SS, Total_SE

Tabel 8 Hasil Uji Simultan pengaruh variabel handling complaint dan service excellence terhadap kepuasan Pelanggan

\begin{tabular}{llrrrrr}
\hline \multirow{2}{*}{ Model } & \multicolumn{2}{c}{$\begin{array}{c}\text { Sum of } \\
\text { Squares }\end{array}$} & Df & \multicolumn{2}{c}{ Mean } \\
Square & F & \multicolumn{1}{c}{ Sig. } \\
\hline \multirow{2}{*}{1} & Regression & 373.112 & 2 & 186.556 & 52.968 & $.000^{\mathrm{b}}$ \\
\cline { 2 - 7 } & Residual & 341.638 & 97 & 3.522 & & \\
\cline { 2 - 7 } & Total & 714.750 & 99 & & & \\
\hline
\end{tabular}

a. Dependent Variable: Total_KP

b. Predictors: (Constant), Total_HC, Total_SE 
Tabel 9 Hasil Uji Simultan pengaruh variabel handling complaint dan servicescape terhadap kepuasan Pelanggan

\begin{tabular}{ccccccc}
\hline \multicolumn{2}{c}{ Model } & $\begin{array}{c}\text { Sum of } \\
\text { Squares }\end{array}$ & df & $\begin{array}{c}\text { Mean } \\
\text { Square }\end{array}$ & F & Sig. \\
\hline \multirow{2}{*}{1} & Regression & 338.344 & 2 & 169.172 & 43.596 & $.000^{\mathrm{b}}$ \\
\cline { 2 - 7 } & Residual & 376.406 & 97 & 3.880 & & \\
\cline { 2 - 7 } & Total & 714.750 & 99 & & & \\
\hline
\end{tabular}

a. Dependent Variable: Total_KP

b. Predictors: (Constant), Total_HC, Total_SS

Restaurant's

Customers

Satisfaction

Tabel 10 Hasil Uji Simultan pengaruh variabel handling complaint, service excellence dan servicescape terhadap kepuasan Pelanggan

\begin{tabular}{ccccccc}
2 & Model & $\begin{array}{c}\text { Sum of } \\
\text { Squares }\end{array}$ & df & $\begin{array}{c}\text { Mean } \\
\text { Square }\end{array}$ & F & Sig. \\
\hline \multirow{2}{*}{1} & Regression & 392.820 & 3 & 130.940 & 39.047 & $.000^{\mathrm{b}}$ \\
\cline { 2 - 7 } & Residual & 321.930 & 96 & 3.353 & & \\
\cline { 2 - 7 } & Total & 714.750 & 99 & & &
\end{tabular}

a. Dependent Variable: Total_KP

b. Predictors: (Constant), Total_HC, Total_SS, Total_SE

Berdasarkan tabel 7 diperoleh hubungan antara variabel independen yaitu yang terdiri dari Service Excellence dan Servicescape dengan variabel dependen yaitu Kepuasan Pelanggan dengan $\alpha=5 \%, \mathrm{df} 1=3 \mathrm{df} 2=96$ diperoleh nilai $\mathrm{F}$ hitung sebesar 56,870 dan $\mathrm{F}$ tabel sebesar 2,70 dengan demikian maka $\mathrm{F}$ hitung lebih besar dari $\mathrm{F}$ tabel atau $(56,870>2,70)$. Dengan demikian hipotesis pertama diterima, $\mathrm{H} 0$ ditolak dan $\mathrm{H} 1$ diterima hal ini berarti ada hubungan yang signifikan antara Service Excellence dan Servicescape terhadap Kepuasan Pelanggan

Berdasarkan tabel 8 diperoleh hubungan antara variabel independen yaitu yang terdiri dari Service Excellence dan Handling Complaint dengan variabel dependen yaitu Kepuasan Pelanggan dengan $\alpha=5 \%$, df1 $=3 \mathrm{df} 2=96$, diperoleh nilai $\mathrm{F}$ hitung sebesar 52,968 dan $\mathrm{F}$ tabel sebesar 2,70 dengan demikian maka $\mathrm{F}$ hitung lebih besar dari F tabel atau $(52,968>2,70)$. Dengan demikian hipotesis pertama diterima, $\mathrm{H} 0$ ditolak dan $\mathrm{H} 1$ diterima hal ini berarti ada hubungan yang signifikan antara Service Excellence dan Handling Complaint terhadap Kepuasan Pelanggan

Berdasarkan tabel 9 diperoleh hubungan antara variabel independen yaitu yang terdiri dari Servicescape dan Handling Complaint dengan variabel dependen yaitu Kepuasan Pelanggan dengan $\alpha=5 \%, \mathrm{df} 1=3 \mathrm{df} 2=96$, diperoleh nilai $\mathrm{F}$ hitung sebesar 43,596 dan $\mathrm{F}$ tabel sebesar 2,70 dengan demikian maka $\mathrm{F}$ hitung lebih besar dari F tabel atau $(43,596>2,70)$. Dengan demikian hipotesis pertama diterima, $\mathrm{H} 0$ ditolak dan $\mathrm{H} 1$ diterima hal ini berarti ada hubungan yang signifikan antara Servicescape dan Handling Complaint terhadap Kepuasan Pelanggan

Berdasarkan tabel 10 diperoleh hubungan antara variabel independen yaitu yang terdiri dari Service Excellence, Servicescape, Handling Complaint dengan variabel dependen yaitu Kepuasan Pelanggan dengan $\alpha=5 \%$, df1 $=3 \mathrm{df} 2=96$, diperoleh nilai $\mathrm{F}$ hitung sebesar 39,047 dan $\mathrm{F}$ tabel sebesar 2,70 dengan demikian maka $\mathrm{F}$ hitung lebih besar dari F tabel atau $(39,047>2,70)$. Dengan demikian hipotesis pertama diterima, $\mathrm{H} 0$ ditolak dan $\mathrm{H} 1$ diterima hal ini berarti ada hubungan yang signifikan antara Service Excellence, Servicescape dan Handling Complaint terhadap Kepuasan Pelanggan.

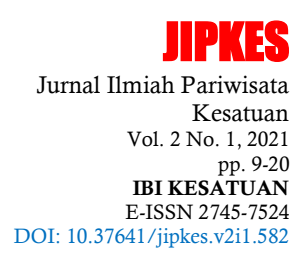


Restaurant's

Customer

Satisfaction

18

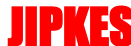

Jurnal Ilmiah Pariwisata

Kesatuan

Vol. 2 No. 1, 2021

pp. $9-20$

IBI KESATUAN

E-ISSN 2745-7524

DOI: $10.37641 /$ jipkes.v2i1.582
Pengaruh Service Excellence (X1) terhadap Kepuasan Pelanggan

Penelitian ini berdasarkan hasil uji statistik diatas, hipotesis pertama yang berbunyi terdapat hubungan antara Service Excellence terhadap Kepuasan Pelanggan dapat diterima, hal ini ditunjukan dengan nilai t-hitung sebesar 4,031 yang dimana lebih besar dibandingkan dengan $\mathrm{T}$ tabel sebesar 1,984 dan nilai signifikansi 0,000 lebih kecil dibandingkan 0,05 yang dimana variabel tersebut berpengaruh positif dan signifikan terhadap Kepuasan Pelanggan maka hipotesis satu diterima. Hasil ini sejalan dengan hasil penelitian dari Yusri Abdillah (2015) yang berjudul PENGARUH EXCELLENT SERVICE TERHADAP KEPUASAN PELANGGAN SERTA DAMPAKNYA PADA LOYALITAS PELANGGAN (Survei pada Pelanggan Pizza Hut Malang Town Square) bahwa Service Excellence menunjukan adanya pengaruh positif dan signifikan terhadap Kepuasan Pelanggan.

\section{Pengaruh Servicescape (X2) terhadap Kepuasan Pelanggan}

Penelitian ini berdasarkan hasil uji statistik diatas, hipotesis kedua yang berbunyi terdapat hubungan antara Servicescape terhadap Kepuasan Pelanggan dapat diterima, hal ini ditunjukan dengan nilai t-hitung sebesar 2,424 yang dimana lebih besar dibandingkan dengan $\mathrm{T}$ tabel sebesar 1,984 dan nilai signifikansi 0,017 lebih kecil dibandingkan 0,05 yang dimana variabel tersebut berpengaruh positif dan signifikan terhadap Kepuasan Pelanggan maka hipotesis dua diterima. Hasil ini sejalan dengan hasil penelitian dari Achmad Fauzi DH Kadarisman Hidayat (2015) yang berjudul PENGARUH SERVICESCAPE (LINGKUNGAN LAYANAN) TERHADAP KEPUASAN DAN DAMPAKNYA PADA LOYALITAS PELANGGAN bahwa Servicescape menunjukan adanya pengaruh positif dan signifikan terhadap Kepuasan Pelanggan.

\section{Pengaruh Handling Complaint (X3) terhadap Kepuasan Pelanggan}

Penelitian ini berdasarkan hasil uji statistik diatas, hipotesis ketiga yang berbunyi terdapat hubungan antara Handling Complaint terhadap Kepuasan Pelanggan dapat diterima, hal ini ditunjukan dengan nilai t-hitung sebesar 1,451 yang dimana lebih kecil dibandingkan dengan $\mathrm{T}$ tabel sebesar 1,984 dan nilai signifikansi 0,150 lebih besar dibandingkan 0,05 yang dimana variabel tersebut berpengaruh positif namun tidak signifikan terhadap Kepuasan Pelanggan maka hipotesis tiga diterima. Hasil ini sejalan dengan hasil penelitian dari Susi Indriyani, Selvy (2009) yang berjudul PENGARUH PENANGANAN KELUHAN (COMPLAINT HANDLING) TERHADAP KEPERCAYAAN DAN KOMITMEN MAHASISWA PADA PERGURUAN TINGGI SWASTA DI BANDAR LAMPUNG, bahwa Handling Complaint menunjukan adanya pengaruh positif dan signifikan terhadap Kepuasan Pelanggan.

\section{PENUTUP}

Pengaruh Service Excellence, Servicescape, dan Handling Complaint terhadap Kepuasan Pelanggan Studi Kasus Pada Restoran Cimory Riverside, maka dapat disimpulkan sebagai berikut :

1. Variabel Service Excellence (X1) memiliki pengaruh terhadap Kepuasan Pelanggan (Y). Hasil pengujian statistik menunjukan bahwa Service Excellence berpengaruh positif dan terdapat hubungan yang signifikan terhadap Kepuasan Pelanggan. Artinya, adanya Kepuasan Pelanggan pada layanan Restoran Cimory Riverside dapat dijelaskan oleh baiknya layanan yang diberikan pada saat berkunjung ke Restoran Cimory Riverside. Hal ini berarti semakin tinggi Service Excellence maka akan semakin tinggi Kepuasan Pelanggan. 
2. Vaiabel Servicescape (X2) memiliki pengaruh terhadap Kepuasan Pelanggan (Y). Hasil pengujian statistik menunjukan bahwa Servicescape berpengaruh positif dan signifikan terhadap Kepuasan Pelanggan. Artinya, adanya Kepuasan Pelanggan pada layanan Restoran Cimory Riverside dapat dijelaskan oleh lingkungan layanan yang baik dan memadai yang diberikan oleh Restoran Cimory Riverside sesuai dengan kualitas layanan yang diberikan. Hal ini berarti semakin tinggi Servicescape maka akan semakin tinggi Kepuasan Pelanggan.

3. Variabel Handling Complaint (X3) memiliki pengaruh terhadap Kepuasan Pelanggan (Y). hasil pengujian statistik menunjukan bahwa Handling Complaint berpengaruh positif namun tidak signifikan terhadap Kepuasan Konsumen. Artinya, adanya Kepuasan Pelanggan pada Restoran Cimory Riverside dapat dijelaskan oleh penanganan keluhan yang diberikan Restoran Cimory Riverside karena karyawan melakukan tugasnya sesuai prosedur yang ada. Hal ini berarti semakin tinggi Kepercayan Konsumen makan akan semakin tinggi Kepuasan Pelanggan.

4. Service Excellence (X1) dan Servicescape (X2) memiliki pengaruh terhadap Kepuasan Pelanggan (Y). Hasil pengujian statistik menunjukan bahwa Service Excellence dan Servicescape memiliki pengaruh positif dan signifikan terhadap Kepuasan Pelanggan. Artinya, kedua variabel independen disimpulkan bahwa hipotesis keempat yang menyatakan dugaan adanya pengaruh terhadap dependen dapat diterima.

5. Service Excellence (X1) dan Handling Complaint (X3) memiliki pengaruh terhadap Kepuasan Pelanggan (Y). Hasil pengujian statistik menunjukan bahwa Service Excellence dan Handling Complaint memiliki pengaruh positif dan signifikan terhadap Kepuasan Pelanggan. Artinya, kedua variabel independen disimpulkan bahwa hipotesis kelima yang menyatakan dugaan adanya pengaruh terhadap dependen dapat diterima.

6. Servicescape (X2), dan Handling Complaint (X3) memiliki pengaruh terhadap Kepuasan Pelanggan (Y). Hasil pengujian statistik menunjukan bahwa Servicescape, dan Handling Complaint memiliki pengaruh positif dan signifikan terhadap Kepuasan Pelanggan. Artinya, kedua variabel independen disimpulkan bahwa hipotesis keenam yang menyatakan dugaan adanya pengaruh terhadap dependen dapat diterima.

7. Service Excellence (X1), Servicescape (X2), dan Handling Complaint (X3) memiliki pengaruh terhadap Kepuasan Pelanggan (Y). Hasil pengujian statistik menunjukan bahwa Service Excellence, Servicescape, dan Handling Complaint memiliki pengaruh positif dan signifikan terhadap Kepuasan Pelanggan. Artinya, ketiga variabel independen disimpulkan bahwa hipotesis ketujuh yang menyatakan dugaan adanya pengaruh terhadap dependen dapat diterima.

\section{DAFTAR PUSTAKA}

[1] Atep, Adya Barata. 2011. Dasar - dasar Pelayanan Prima. Jakarta: Elex Media Komputindo

[2] Daryanto dan Setyobudi, I. 2014. Konsumen dan Pelayanan Prima. Yogyakarta. Gava Media.

[3] Ghozali, Imam. 2009. Aplikasi Analisis Multivariate dengan Program SPSS. Semarang: UNDIP.

[4] Gummesson. 2011. Pemasaran Jasa (Seventh ed.). Jakarta. Erlangga

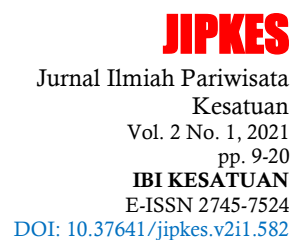


Restaurant's

Customer

Satisfaction

20

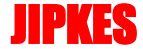

Jurnal Ilmiah Pariwisata Kesatuan Vol. 2 No. 1, 2021 pp. $9-20$

IBI KESATUAN

E-ISSN 2745-7524 DOI: $10.37641 /$ jipkes.v2i1.582
[5] Hightower, Jr, R., \& Shariat, M. 2009. Servicescape's Hierarchial Factor Structure Model. Global Review of Business and Economic Research. Serial Publication

[6] Hurriyati, R. 2010. Bauran Pemasaran dan Loyalitas Konsumen. Jakarta. Alfabetha.

[7] Kotler, Philip \& Keller, K. 2012. Manajamen Pemasaran Edisi 13, Jilid 1 dan 2. Jakarta: Erlangga

[8] Lovelock, Christopher, Jochen Wirtz, \& Jacky Mussry. 2011. Pemasaran Jasa. edisi 7. Jakarta. Erlangga

[9] Saladin, Djaslim. 2012, Manajemen Pemasaran, Analisis Perencanaan Pelaksanaan, Unsur-unsur Pemasaran, CV. Linda Karya, Bandung

[10] Sumarni, Murti dan Soeprihanto, John. 2010. Pengantar Bisnis (Dasar-dasar Ekonomi Perusahaan). Edisi ke 5. Liberty Yogyakrta

[11] Tjiptono, Fandy. 2011. Strategi Pemasaran. Edisi 3. Andi

[12] Tjiptono, Fandy dan Chandra, Gregorius. 2012. Pemasaran Stratejik Edisi 2. Andi. Bandung

[13] Tjiptono, Fandy. 2012. Service Management Mewujudkan Pelayanan Prima. Andi. Bandung

[14] Valerie A. Zeithaml \& Mary Jo Bitner. 2008. Service Marketing. The McGraw Hill Companies, Inc

[15] Hapsari Annisa Mirandha, Kumadji Srikandi dan Abdillah Yusri. 2015. Pengaruh Excellent Service Terhadap Kepuasan Pelanggan Serta Dampaknya Pada Loyalitas Pelanggan (Survei pada Pelanggan Pizza Hut Malang Town Square) Fakultas Ilmu Administrasi Universitas Brawijaya Malang.

[16] Pramita Cempaka Dyah, Fauzi DH Achmad dan Hidayat Kadarisman. 2015. Pengaruh Servicescape Terhadap Kepuasan Dan Dampaknya Pada Loyalitas Nasabah. Fakultas Ilmu Administrasi Universitas Brawijaya Malang.

[17] Laurena, Deby Julia 2015. Analisi Pelayanan Prima Dengan Konsep A6 Pada Perpusatakan Tinggi Negri di Surabaya. Ilmu Informasi dan Perpustakaan Fakultas Ilmu Sosial dan Politik Universitas Airlangga.

[18] Meika Putra Pratama, Retno Setyorini, ST., MM. 2015. Pengaruh Servicescape Terhadap Kepuasan Konsumen Kafe Roti Gempol dan Kopi Anjis Cabang Jalan Bangawan. Program Studi S-1 Ilmu Administrasi Bisnis Fakultas Komunikasi dan Bisnis, Universitas Telkom

[19] Nyoman Suparmanti Asih. 2016. Pengaruh Pelayanan Prima Terhadap Kepuasan Pelanggan Salon Agata Singaraja. Program Studi Pendidikan Ekonomi, Fakultas Ekonomi Universitas Pendidikan Ganesha Singaraja, Indonesia

[20] Putri, Isma Rachmadhani. 2015. Tinjauan Atas Penanganan Keluhan Pelanggan Pada PT. Tauba Zakka (Tazkia Tours \& Travel). Program Studi Manajemen Pemasaran Diploma III Sekolah Tinggi Ilmu Ekonomi Kesatuan.

[21] Setyawan, Suci. 2012. Penanganan Pengaduan (Complaint Handling) Dalam Pelayanan Publik (Studi Tentang Transparansi, Responsivitas, Dan Akuntabilitas Dalam Penanganan Pengaduan di Kantor Pertanahan Kota Surabaya II). Program Studi Ilmu Administrasi Negara, FISIP, Universitas Airlangga. 